\title{
Preoperative risk factors for acute kidney injury after liver transplantation: results from a cross-sectional study in Northeast of Brazil
}

\author{
Raimundo Martins GOMES JUNIOR ${ }^{1}$, Lia Cavalcante CEZAR ${ }^{1}$, Gdayllon Cavalcante MENESES ${ }^{2}$, \\ Geraldo Bezerra da SILVA JUNIOR ${ }^{3}$, José Huygenes Parente GARCIA ${ }^{4}$ and Elizabeth De Francesco DAHER ${ }^{5}$
}

\begin{abstract}
Background - Acute kidney injury (AKI) is a common complication in the immediate postoperative period of patients undergoing liver transplantation. Objective - The aim of this study was to evaluate preoperative risk factors for AKI after liver transplantation. Methods - A cross-sectional study was conducted with adults submitted to orthotopic liver transplantation at a reference hospital in Fortaleza, Northeast of Brazil, from January to December 2016. Preoperative risk factors were evaluated for AKI development in the immediate postoperative period. AKI was defined according to the Kidney Disease: Improving Global Outcomes (KDIGO) criteria. Results - A total of 40 patients were included in the study. AKI was found in $85 \%$ of patients in the first 24 hours after transplantation, most of them (40\%) classified in KDIGO stage 1. Preoperative data indicate that serum albumin levels were lower in the KDIGO stage 3 group compared to the non-AKI group, as well as the hematocrit levels. Direct bilirubin (DB) was higher in the KDIGO stage 3 group compared to the group without AKI, as well as alkaline phosphatase (AP) and gamma-glutamiltransferase (GGT). In a logistic regression analysis independent risk factors for AKI were increase levels of AP, GGT and DB and decrease level of serum albumin. Conclusion - Low levels of serum albumin, and elevated levels of DB, AP and GGT in the preoperative period are risk factors for AKI development after liver transplantation.
\end{abstract}

HEADINGS - Liver transplantation. Acute kidney injury. Risk factors. Prognosis.

\section{INTRODUCTION}

Acute kidney injury (AKI) is a common complication in the immediate postoperative period of patients undergoing liver transplantation, with varying incidence ${ }^{(1)}$. Past studies have found AKI in $12 \%$ to $95 \%$ of patients after liver transplantation ${ }^{(2)}$, with $8 \%-17 \%$ requiring renal replacement therapy, and it is associated with worse outcomes ${ }^{(3)}$.

AKI etiology after liver transplantation is variable and depends on multiple factors, as acute tubular necrosis secondary to renal ischemia, drug nephrotoxicity (antibiotics and immunosuppressants), and previous patients' clinical conditions related to the degree of hepatic decompensation or the presence of hepatorenal syndrome ${ }^{(4)}$.

The degree of hepatic decompensation plays an important role in the pathophysiology of AKI not only due to hemodynamic abnormalities, but also as a consequence of inflammatory process secondary to cirrhosis complications, such as sepsis, and due to associated comorbidities such as virus $\mathrm{C}$ hepatitis. Proinflammatory cytokines have been studied and are associated with AKI development after liver transplantation ${ }^{(5,6)}$.

The aim of this study was to investigate preoperative risk factors for AKI after orthotopic liver transplantation.

\section{METHODS}

A cross-sectional study was performed in adults submitted to orthotopic liver transplantation at a reference hospital in Fortaleza city, Ceará, Northeast of Brazil, from January to December 2016. The study protocol was reviewed and approved by the Ethics Committee of the Hospital Universitário Walter Cantídio, Universidade Federal do Ceará, Brazil.

Exclusion criteria were: patients under 18 years of age; glomerular filtration rate $<60 \mathrm{~mL} / \mathrm{min} / 1.73 \mathrm{~m}^{2}$ previous to transplantation; $\mathrm{AKI}$ at the current hospital admission, previous to the transplantation; simultaneous hepatic and renal transplantation, or hepatic and pancreas transplantation; use of nephrotoxic drugs, except those used in the specific treatment of transplantation, such as immunosuppressants.

Clinical data collected from patients were: age, gender, history of systemic arterial hypertension and diabetes mellitus, habits (alcoholism, smoking, use of illicit drugs), CHILD-PUGH classification and MELD (model for end-stage liver disease) score. Preoperative laboratory evaluation included serum urea, creatinine, sodium, potassium, serum albumin, serum glucose, total bilirubin and their fractions, aspartate aminotransferase (AST), alanine aminotransferase (ALT), alkaline phosphatase

Declared conflict of interest of all authors: none

Disclosure of funding: no funding received.

${ }^{1}$ Divisão de Anestesiologia, Hospital Universitário Walter Cantidio, Universidade Federal do Ceará, Fortaleza, CE, Brasil; ${ }^{2}$ Programa de Pós-Graduação em Farmacologia, Departamento de Fisiologia e Farmacologia, Faculdade de Medicina, Universidade Federal do Ceará, Fortaleza, CE, Brasil; ${ }^{3}$ Faculdade de Medicina, Programa de Pós-Graduação em Saúde Pública, Centro de Ciências da Saúde, Universidade de Fortaleza, CE, Brasil; ${ }^{4}$ Departamento de Cirurgia, Faculdade de Medicina, Universidade Federal do Ceará, Fortaleza, CE, Brasil; ${ }^{5}$ Departamento de Medicina Interna, Faculdade de Medicina da Universidade Federal do Ceará, Fortaleza, CE, Brasil.

Correspondence: Elizabeth De Francesco Daher. Rua Vicente Linhares, 1198. CEP: 60135-270 - Fortaleza, CE, Brasil. E-mail: ef.daher@uol.com.br 
(ALP) gamma-glutamyltransferase (GGT), APTT (activated partial thromboplastin time), cholesterol, triglycerides, hemoglobin, hematocrit, platelet count.

AKI was evaluated in the first 24 hours after liver transplantation and defined according to Kidney Disease: Improving Global Outcomes (KDIGO) criteria as an increase from 1.5 to 1.9 fold or greater than or equal to $0.3 \mathrm{mg} / \mathrm{dL}$ above the baseline creatinine (KDIGO stage 1); increase from 2 to 2.9 times the baseline creatinine (KDIGO 2); increase greater than three times the baseline creatinine or greater than or equal to $4 \mathrm{mg} / \mathrm{dL}$ or renal replacement therapy need (KDIGO 3) ${ }^{(7,8)}$. AKI can also be defined by urinary flow change: less than $0.5 \mathrm{~mL} / \mathrm{kg} /$ hour for 6 hours (KDIGO 1); Less than $0.5 \mathrm{~mL} / \mathrm{kg} /$ hour for 12 hours (KDIGO 2); Less than 0.3 $\mathrm{mL} / \mathrm{kg} /$ hour for 24 hours or anuria for 12 hours (KDIGO 3). In this study only the change in serum creatinine was evaluated since urinary flow data were not available for all patients.

Statistical analyzes were performed with the SPSS program version 20.0 (IBM, USA). Pearson's chi-square test was applied for tests of association and homogeneity in the distribution of categorized data. For the quantitative variables, the analysis was done by observing the minimum and maximum values, calculation of means and standard deviations. The Shapiro-Wilk test was used to verify the normal distribution of the continuous variables. Student's t-test (parametric test) was applied to compare independent groups. For comparison of three or more independent groups the ANOVA (parametric test) was used. In a logistic regression, univariate and multivariate models was used for assessing the independent risk factors for AKI. Significance level was set on $5 \%(P<0.05)$.

\section{RESULTS}

A total of 40 patients were included, with a mean age of 53 years (range 19-72), and 22 were males $(53 \%)$. The incidence of systemic arterial hypertension was $18.8 \%$ and diabetes mellitus was $20.5 \%$. AKI was observed in 34 cases in the first 24 hours after transplantation (85\%) (TABLE 1).

TABLE 1. Clinical characteristics of 40 patients evaluated in the post-liver transplantation. Fortaleza, Ceará, Brazil, 2016

\begin{tabular}{lcc}
\hline & N & $\%$ \\
\hline Gender & 22 & \\
Male & 18 & 55 \\
Female & 34 & 45 \\
Acute kidney injury & 16 & 85 \\
KDIGO 1 & 9 & 40 \\
KDIGO 2 & 9 & 22.5 \\
KDIGO 3 & & 22.5 \\
Comorbidities & 8 & \\
Diabetes mellitus & 9 & 20.5 \\
Systemic arterial hypertension & 7 & 18.8 \\
Smoking & 20 & 18.4 \\
Alcoholism & 1 & 53.6 \\
Use of illicit drugs & & 2.6 \\
Classification CHILD-PUGH & 6 & \\
A & 13 & 16.2 \\
B & 18 & 48.6 \\
C
\end{tabular}

KDIGO: Kidney Disease: Improving Global Outcomes criteria
There was a higher frequency of CHILD C classification among those with AKI, and there was no significant difference in the other parameters evaluated (TABLE 2). The preoperative predictors of AKI were low serum albumin, low hematocrit value and high values of direct bilirubin, alkaline phosphatase and gamma-glutamyltransferase $(P<0.05)$ (TABLE 3$)$. These laboratory changes were more significant among patients with KDIGO stage 3 compared to the non-AKI group: low serum albumin $(2.8 \pm 0.3$ vs $3.48 \pm 0.48, P<0.05)$, low hematocrit value $(25 \pm 10$ vs $37 \pm 4.8$, $P<0.05)$, high direct bilirubin $(7.9 \pm 6.9$ vs $1.95 \pm 3.7, P<0.05)$, high alkaline phosphatase $(658 \pm 421$ vs $218 \pm 199, P<0.05)$ and gammaglutamyltransferase $(371 \pm 185$ vs $167 \pm 142, P<0.05)$.

Independent risk factors for AKI were increase in alkaline phosphatase, gamma-glutamyltransferase and direct bilirubin levels, while albumin levels were protective factor (normal or high levels of albumin were associated with less risk of AKI). All Odds ratio and confidence interval values were described in TABLE 4.

\section{DISCUSSION}

Liver transplantation is the only treatment option for terminal liver disease. AKI is a common complication following liver transplantation, which was found in a high proportion of patients in our study. There are many intraoperative risk factors related to the surgical technique and clinical conditions such as hemodynamic status and hydroelectrolytic disorders ${ }^{(9)}$. Postoperative risk factors include immunosuppressive drugs, infectious complications, use of antibiotics, sepsis, prolonged hypotension and use of radiological contrasts $^{(10)}$. Preoperative risk factors were evaluated in the present study and seem to be related to the overall bad clinical condition of patients at the time they will undergo the liver transplantation.

The piggyback technique was performed in all cases, and there was no difference between the group AKI or not AKI about the surgery duration, what was also observed in a study performed by Sirivatanauksorn et al. ${ }^{(11)}$.

In patients with $\mathrm{AKI}$, according to the KDIGO classification, pre-operative hematocrit was lower $(P<0.05)$. In a study performed by Erdost et al. ${ }^{(7)}$, the pre-operative hemoblobin level was also lower in patients with acute renal injury (ARI) using risk, injury, failure, loss, and end-stage renal failure (RIFLE) classification and these patients received significantly more red blood cells (RBC) and fresh-frozen plasma (FFP). The ARI rate increased according to

TABLE 2. Comparison of the clinical characteristics of patients evaluated in the post-liver transplantation according to the occurrence of acute renal injury. Fortaleza, Ceará, Brazil, 2016

\begin{tabular}{lccc}
\hline & $\begin{array}{c}\text { AKI* } \\
(\mathbf{n}=34)\end{array}$ & $\begin{array}{c}\text { Non-AKI } \\
(\mathbf{n}=6)\end{array}$ & $P$ \\
\hline Gender & $18(52.9 \%)$ & $4(66.7 \%)$ & 0.53 \\
$\quad$ Male & $16(47.1 \%)$ & $2(33.3 \%)$ & \\
$\quad$ Female & & & \\
Comorbidities & $6(18.2 \%)$ & $2(33.3 \%)$ & 0.39 \\
$\quad \begin{array}{c}\text { Diabetes mellitus } \\
\text { Systemic arterial hypertension }\end{array}$ & 0 & $9(26.5 \%)$ & 0.15 \\
Smoking & $5(15.2 \%)$ & $2(40 \%)$ & 0.18 \\
Alcoholism & $4(30 \%)$ & $16(48.5 \%)$ & 0.69 \\
Use of illicit drugs & 0 & $1(3 \%)$ & 0.69 \\
Classification CHILD-PUGH & & & \\
A & $3(9.7 \%)$ & $3(50 \%)$ & \\
B & $11(35.5 \%)$ & $2(33.3 \%)$ & $0.03 *$ \\
C & $17(54.8 \%)$ & $1(16.7 \%)$ & \\
\hline AKI: acute renal injury. Fisher's test, significant $P<0.05$ & &
\end{tabular}


TABLE 3. Comparison of laboratory data of patients evaluated in the preoperative period according to the occurrence of acute renal injury after liver transplantation. Fortaleza, Ceará, Brazil, 2016

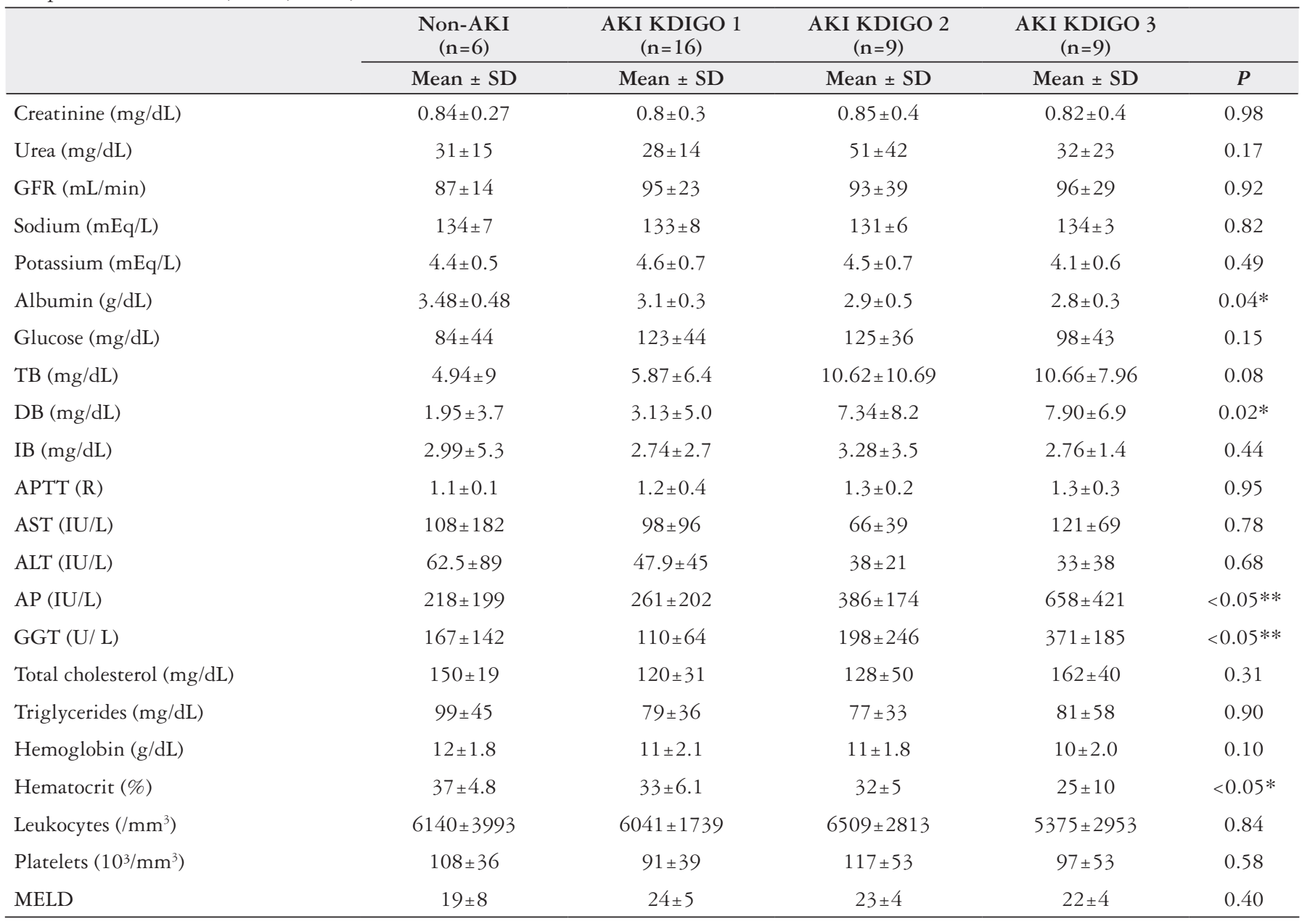

AKI: acute renal injury; KDIGO: Kidney Disease: Improving Global Outcomes criteria; GFR: glomerular filtration rate (mL/min/1.73m²); TB: total bilirubin; DB: direct bilirubin; IB: indirect bilirubin; APTT: activated partial thromboplastin time (R: patient/control ratio); AST: aspartate aminotransferase; ALT: alanine aminotransferase; AP: alkaline phosphatase; GGT: gamma-glutamyltransferase; MELD: model for end-stage liver disease. ANOVA test was used for all variables. $* P<0.05$ in AKI-KDIGO 3 vs Non-AKI; $* *<<0.05$ in AKI-KDIGO 3 vs Non-AKI and AKI-KDIGO 1.

TABLE 4. Evaluation of preoperative risk factors in univariate and multivariate models for severe acute kidney injury development

\begin{tabular}{|c|c|c|c|}
\hline & Univariate analysis & Model 1 & Model 2 \\
\hline & OR $(95 \% \mathrm{CI})$ & OR $(95 \% \mathrm{CI})$ & OR $(95 \% \mathrm{CI})$ \\
\hline Age (year) & $0.976(0.919-1.037)$ & $0.974(0.915-1.037)$ & $0.974(0.902-1.051)$ \\
\hline Gender (male) & $1.042(0.298-3.645)$ & $1.192(0.314-4.525)$ & $2.244(0.327-15.392)$ \\
\hline MELD (perunit) & $1.002(0.886-1.132)$ & $1.001(0.882-1.137)$ & $1.117(0.926-1.348)$ \\
\hline Surgery time (hour) & $0.576(0.258-1.287)$ & $0.532(0.229-1.237)$ & $0.340(0.106-1.088)$ \\
\hline Hematocrit (\%) & $0.884(0.784-0.998) *$ & $0.884(0.780-1.002)$ & $0.924(0.758-1.127)$ \\
\hline Hemoglobin (g/dL) & $0.703(0.492-1.004)$ & $0.713(0.496-1.024)$ & $0.705(0.459-1.083)$ \\
\hline Sodium (mEq/L) & $0.990(0.900-1.094)$ & $0.992(0.895-1.100)$ & $1.061(0.901-1.249)$ \\
\hline Potassium (mEq/L) & $0.604(0.228-1.598)$ & $0.567(0.184-1.742)$ & $0.757(0.178-3.220)$ \\
\hline Alkaline phosphatase* (per 50 IU/L) & $1.315(1.039-1.664) *$ & $1.431(1.083-1.892) *$ & $1.013(1.002-1.025)^{*}$ \\
\hline Gamma-glutamyltransferase* (per $10 \mathrm{IU} / \mathrm{L})$ & $1.352(1.029-1.778) *$ & $1.405(1.035-1.908) *$ & $1.012(0.994-1.030)$ \\
\hline Direct bilirubin* (mg/dL) & $1.151(1.011-1.310)^{*}$ & $1.209(1.027-1.432) *$ & $1.232(1.016-1.494)^{*}$ \\
\hline Albumin* (per each $0.5 \mathrm{~g} / \mathrm{dL}$ ) & $0.117(0.030-0.451)^{*}$ & $0.118(0.030-0.464)^{*}$ & $0.014(0.0001-0.661) *$ \\
\hline
\end{tabular}

Model 1: age, gender, MELD classification. Model 2: age, gender, MELD classification, surgery time, hemoglobin, platelets, leukocytes, serum sodium and potassium. $* P<0.05$. 
the RIFLE classification if pre-operative hemoglobin level was $<9$ g/dL (OR, 2.830; 95\% CI, 1.157e6.926). However, no similar relationship was detected between pre-operative hemoglobin level and acute kidney injury network (AKIN) or KDIGO classifications. In our study, the pre-operative hemoglobin level was lower in AKI group (TABLE 3).

Most cases of AKI observed in this study were classified in the KDIGO stage 1, reflecting a mild kidney injury. However, recent evidence suggests that even mild/early-stage AKI can lead to serious complications such as prolonged hospital stay, intensive care unit admission need and increased mortality ${ }^{(12)}$, so it is important to identify these patients and provide early specific support for kidney health, including adequate fluid support, electrolyte imbalance correction and avoidance of nephrotoxic drugs use.

There was an association between AKI development and the severity of liver disease, as assessed by the CHILD-PUGH score, which was also observed in previous study ${ }^{(13)}$. This is an expected finding since the severity of liver disease is related to pathophysiological changes that compromise glomerular filtration rate: blood pressure is reduced, renal adrenergic tone is increased, cardiac performance is reduced as a consequence of volume overload, the synthesis of vasoprotective peptides is reduced and intra-abdominal pressure is elevated in the context of portal hypertension ${ }^{(14)}$. Traditionally, these hemodynamic changes secondary to cirrhosis were the only factors responsible for changes in renal function. It is also known that renal dysfunction in cirrhotic patients can be triggered by inflammatory processes. Inflammatory mediators, derived from response to pathogens or from immune cell activation secondary to the underlying disease itself, can cause microcirculatory disorders and consequent oxidative stress and renal tubular injury ${ }^{(3)}$.

In the present study, the MELD classification was not a risk factor for AKI development. Patients with previously impaired renal function were excluded from this study. This is perhaps the reason why patients with elevated MELD had no significance for the AKI development in the postoperative period, since patients with the highest MELD scores have already developed AKI in the preoperative period or have already developed chronic kidney disease during preparation for liver transplantation. Also noteworthy is the additional score on the MELD scale that patients with hepatocellular carcinoma receive for allocation in the national organ donation ranking, which overestimate the severity of the liver disease, and may be a factor of bias. In our study, the prevalence of hepatocarcinoma was high $(27.5 \%)$.

Comparing group AKI vs no-AKI, there were significantly more patients CHILD C in AKI group (54.8\%) than in no AKI (16.7\%). Klaus et al. ${ }^{(1)}$ did not found Child- Pugh score as an independent risk factor, however it was used the AKIN classification, with no relationship with RIFLE or KDIGO.

Several studies have shown an association between pre- LT MELD score and post-LT AKI. Especially patients with high MELD-scores are found to have a significantly increased risk of post-LT AKI ${ }^{(15)}$. In this study, MELD scores, as a quantitative variable presented no significant difference between patients with or without AKI. However, MELD was more useful if used as a qualitative variable, associated with severe AKI (need for dialysis) ${ }^{(10)}$. A possibly cut-off level of 22 was useful to determine which patients were at risk of developing severe renal dysfunction. In the present study mean MELD was 22, which reflects the worse condition of liver function in our patients.

There was a significant association between reduced preoperative values of serum albumin and the development of AKI, with the most significant changes found in the more advanced AKI stages. The relationship between hepatic dysfunction and hypoalbuminemia is well known, but between hypoalbuminemia and AKI is less clear. A meta-analysis showed that hypoalbuminemia was an independent risk factor for the development of $\mathrm{AKI}^{(16)}$. A study developed by Garcia-Martinez et al. ${ }^{(17)}$ showed that albumin infusion in patients with AKI and acute on chronic kidney disease reduces inflammation and oxidative stress, with an improvement in endothelial function and renal blood flow, supporting the role of inflammation in the pathogenesis of AKI.

There was also a significant difference between the preoperative laboratory tests in relation to direct bilirubin, alkaline phosphatase and gamma-glutamyltransferase, with higher levels in the more advanced stages of AKI and in relation to hematocrit (lower levels in AKI patients). This finding reinforces the positive association of AKI with the degree of hepatic dysfunction.

The aim of this study was to evaluate the pre-operative risk factors of AKI in patients undergoing liver transplantation; and, because of this, it was not discussed the immunosuppression therapy.

In conclusion, the present study showed that AKI is a frequent complication in the immediate postoperative period of patients undergoing liver transplantation. There is an important association between the severity of liver disease (in the preoperative period) and AKI development. Low levels of serum albumin, high levels of direct bilirubin, alkaline phosphatase and gammaglutamyltransferase are risk factors for AKI development after liver transplantation. Better strategies to prevent this complication are urgently required, including a careful renal support and kidney function optimization before liver transplantation.

\section{ACKNOWLEDGEMENTS}

We would like to thank Conselho Nacional de Desenvolvimento Científico e Tecnológico $(\mathrm{CNPq})$ for financial support to Elizabeth Daher.

\section{Authors' contributions}

Gomes Junior RM, Cezar LC, Silva Junior GB, Daher EF: conception and design; Gomes Junior RM, Cezar LC, Meneses GC, Silva Junior GB, Garcia JHP, Daher EF: analysis and interpretation of the data; Cezar LC, Meneses GC, Silva Junior GB, Daher EF: drafting of the article; Silva Junior GB, Garcia JHP, Daher EF: critical revision of the article for important intellectual content; Gomes Junior RM, Cezar LC, Meneses GC, Silva Junior GB, Garcia JHP, Daher EF: final approval of the article. 
Gomes Junior RM, Cezar LC, Meneses GC, Silva Junior GB, Garcia JHP, Daher EF. Fatores de risco pré-operatórios para lesão renal aguda após transplante hepático: resultados de um estudo transversal no Nordeste do Brasil. Arq Gastroenterol. 2018;55(1):18-22.

RESUMO - Contexto - Lesão renal aguda (LRA) é uma complicação comum no pós-operatório imediato do transplante hepático. Objetivo-O objetivo foi avaliar os fatores de risco pré-operatórios para LRA após o transplante hepático. Métodos - Foi realizado estudo transversal com adultos submetidos a transplante hepático ortotópico em um hospital de referência em Fortaleza, Nordeste do Brasil, de janeiro a dezembro de 2016. Foram avaliados os fatores de risco pré-operatórios para o desenvolvimento de LRA no pós-operatório. LRA foi definida de acordo com os critérios do Kidney Disease: Improving Global Outcomes (KDIGO). Resultados - Foram incluídos 40 pacientes no estudo. LRA foi encontrada em $85 \%$ dos casos nas primeiras 24 horas após o transplante, sendo a maioria deles (40\%) classificados no estágio KDIGO 1. Os dados pré-operatórios indicaram que os níveis séricos de albumina eram menores nos pacientes no estágio KDIGO 3, em comparação com o grupo sem LRA, bem como os níveis de hematócrito. Os níveis de bilirrubina direta (BD) eram maiores nos pacientes no estágio KDIGO 3 em comparação ao grupo sem LRA, bem como os níveis de fosfatase alcalina (FA) e gama-glutamiltransferase (GGT). Em um modelo de regressão logística, os fatores de risco independentes para LRA foram: níveis elevados de FA, GGT e BD e níveis reduzidos de albumina. Conclusão - Níveis reduzidos de albumina sérica, e níveis elevados de BD, FA e GGT no período pré-operatório são fatores de risco para o desenvolvimento de LRA após o transplante hepático.

DESCRITORES - Transplante de fígado. Lesão renal aguda. Fatores de risco. Prognóstico.

\section{REFERENCES}

1. Klaus F, Keitel da Silva C, Meinerz G, Carvalho LM, Goldani JC, Cantisani G, et al. Acute kidney injury after transplantation: incidence and mortality. Transplant Proc. 2014:46:1819-21.

2. Karapanagiotou A, Kydona C, Dimitriadis C, Sgourou K, Giasnetsova T, Fouzas I, et al. Acute kidney injury after orthotopic liver transplantation. Transplant Proc. 2012;44:2727-9.

3. Wong F. The evolving concept of acute kidney injury in patients with cirrhosis Nat Rev Gastroenterol Hepatol. 2015;12:711-9.

4. Junge G, Schewior LV, Kohler S, Neuhaus R, Langrehr JM, Tullius S, Kahl A, et al. Acute renal failure after liver transplantation: incidence, etiology, therapy, and outcome. Transplant Proc. 2006;38:723-4.

5. Parikh CR, Devarajan P. New biomarkers of acute kidney injury. Crit Care Med 2008;36:S159.

6. Sung WC, Yu HP, Tsai YF, Chung PC, Lin CC, Lee WC. The ratio of plasma interleukin-18 is a sensitive biomarker for acute kidney injury after liver transplantation. Transplant Proc 2014;46:816-8.

7. Erdost HA, Ozkardesler S, Akan M, Iyilikci L, Unek T, Ocmen E, et al. Comparison of the RIFLE, AKIN, and KDIGO Diagnostic Classifications for Acute Renal Injury in Patients Undergoing Liver Transplantation. Transplant Proc. 2016;48:2112-8

8. Kidney Disease: Improving Global Outcomes (KDIGO) Acute Kidney Injury Work Group. KDIGO clinical practice guideline for acute kidney injury. Kidney Int Suppl. 2012;2:1-138

9. Pham PTT, Pham PCT, Wilkinson AH. Managament of renal dysfunction in the liver transplant recipient. Curr Opin Organ Transplant. 2009;14:231-9.
10. Barreto AG, Daher EF, Silva Junior GB, Garcia JH, Magalhães CB, Lima JM, et al. Risk factors for acute kidney injury and 30-day mortality after liver transplantation. Ann Hepatol. 2015;14:688-94.

11. Sirivatanauksorn Y, Parakonthun T, Premasathian N, Limsrichamrern S, Mahawithitwong P, Kositamongkol P, et al. Renal Dysfunction After Orthotopic Liver Transplantation. Transplant Proc. 2014;46:818-21.

12. Hilmi I, Horton CN, Planinsic RM, Sakai T, Nicolau-Raducu R, Damian D, et al. The impact of postreperfusion syndrome on short-term patient and liver allograft outcome in patients undergoing orthotopic liver transplantation. Liver Transplant. 2008; 14:504-8.

13. Hilmi IA, Damian D, Al-Khafaji A, Planinsic R, Boucek C, Sakai T, et al. Acute kidney injury following orthotopic liver transplantation: incidence, risk factors, and effects on patient and graft outcomes. Br J Anaesthes. 2015;114:919-26.

14. Hartleb M, Gutkowski H. Kidneys in chronic liver diseases. World J Gastroenterol. 2012;18:3035-49.

15. de Haan JE, Hoorn EJ, de Geus HRH. Acute Kidney Injury after Liver transplantation: recent insights and future perspectives. Best Pract Res Clin Gastroenterol. 2017;31:161-9.

16. Wiedermann CJ, Wiedermann W, Joannidis M. Hypoalbuminemia and acute kidney injury: a meta-analysis of observational clinical studies. Intensive Care Med. 2010;36:1657-65.

17. Garcia-Martinez R, Noiret L, Sen S, Mookerjee R, Jalan R. Albumin infusion improves renal blood flow autoregulation in patients with acute decompensation of cirrhosis and acute kidney injury. Liver Int. 2014;35:335-43. 